\title{
Installation of Ohio's First Electrolysis-Based Hydrogen Fueling Station
}

\author{
Brianne T. Scheidegger, NASA Glenn Research Center, Cleveland, OH and Michael L. Lively, Greater \\ Cleveland RTA, Cleveland, $\mathrm{OH}$
}

\begin{abstract}
This paper describes progress made towards the installation of a hydrogen fueling station in Northeast Ohio. In collaboration with several entities in the Northeast Ohio area, the NASA Glenn Research Center is installing a hydrogen fueling station that uses electrolysis to generate hydrogen on-site. The installation of this station is scheduled for the spring of 2012 at the Greater Cleveland Regional Transit Authority's Hayden bus garage in East Cleveland. This will be the first electrolysis-based hydrogen fueling station in Ohio.
\end{abstract}

Index Terms - Electrolyzer, energy storage - fuel cells, hydrogen, sensor systems, sustainable development

\section{INTRODUCTION}

$\mathrm{O}$ ver the past decade, the attention paid to the use of fossil fuels and their effects on pollution in the United States has significantly increased. This has been a particular focus in the transportation industry, where almost all vehicles rely on gasoline or diesel fuels to power their engines. A major focus has been on the development of alternative means to power these vehicles, including hybrid electric vehicles (HEV) and full electric vehicles (EV), which run on battery power, and vehicles run off fuel cell power. These methods not only significantly reduce or eliminate the use of fossil fuels, but reduce the pollution associated with burning those fossil fuels. A fuel cell, for example, specifically a proton exchange membrane, or PEM fuel cell, emits only water and heat as byproducts. There is no system exhaust to pollute the air with a PEM fuel cell system. The problem here lies with the lack of methods to easily obtain hydrogen gas needed to power the fuel cell.

As part of NASA's efforts to support renewable and clean energy and to demonstrate the terrestrial benefits of space technology, the Glenn Research Center, by means of the Enabling Technology Development and Demonstration Program, is funding efforts to install a hydrogen fueling station in Cleveland, Ohio. This would be the first electrolysis-based hydrogen fueling station in the state of Ohio, meant to showcase the safe and reliable generation of hydrogen gas via electrolysis while showcasing NASA technologies.

This paper describes the efforts over the past several years to install a hydrogen fueling station in Cleveland, Ohio that uses electrolysis to generate hydrogen gas ${ }^{1}$. The hydrogen gas can then be used to power fuel cell buses, cars, or other utility vehicles and power systems. The Greater Cleveland Regional Transit Authority (GCRTA) will lease a fuel cell bus through United Technologies of Connecticut (UTC) Power which will be powered by a fuel cell consuming hydrogen gas generated at the hydrogen fueling station.

\section{PROJECT BACKGROUND}

\section{A. Project Phase I}

This project began in January of 2009 when the Ohio Aerospace Institute (OAI) was awarded a grant from the Cleveland Foundation. OAI managed the first phase of the program under this grant and collaborated with a design team from NASA GRC with the goals of performing an economic study, outreach activities, and designing and building an electrolyzer to demonstrate the commercial viability of hydrogen gas production as part of a zeroemissions fueling station. Rather than design and build a brand new system, OAI began negotiations with EVermont to obtain components from a decommissioned hydrogen fueling station originally installed by the Department of Energy and British Petroleum (BP) in Burlington, VT in 2006. OAI was able to negotiate with EVermont and purchase this equipment using the available funding from the Cleveland Foundation.

The Greater Cleveland Regional Transit Authority (GCRTA) collaborated with OAI during this initial phase of the project. GCRTA would assume the role of demonstrating the commercial reality of the hydrogen fueling station by running a fuel cell-powered bus, on loan from the United Technologies Corporation (UTC), in revenue service. The GCRTA would also house the bus and maintain both the bus and the fueling station equipment. By GCRTA running a bus in regular revenue

\footnotetext{
${ }^{1}$ This work is supported in part by NASA's Enabling Technology Development \& Demonstration Program's High Efficiency Space Power Systems Project.

This work is supported in part by the Greater Cleveland Regional Transit Authority.

This work was supported in part by a grant from the Cleveland Foundation through the Ohio Aerospace Institute.

Sensor development was funded by NASA SBIR and STTR awards with Makel Engineering, Inc and Case Western Reserve University.
} 
service, data would be collected and fed back to UTC and the public would be directly exposed to fuel cell vehicles and their applications and advantages.

\section{B. Station Equipment}

The equipment purchased by OAI was originally installed in Burlington, VT but had been decommissioned for several years. The station included the following principal components: PEM hydrogen electrolyzer, compressor skid, storage tank array, and hydrogen dispenser. Fig. 1 shows an example of the system dispenser. Since the system had originally been installed in 2006, Proton On-site (formerly Proton Energy Systems, the electrolyzer manufacturer) could not support its use in the current system as subsequent system upgrades had been made to the hardware.

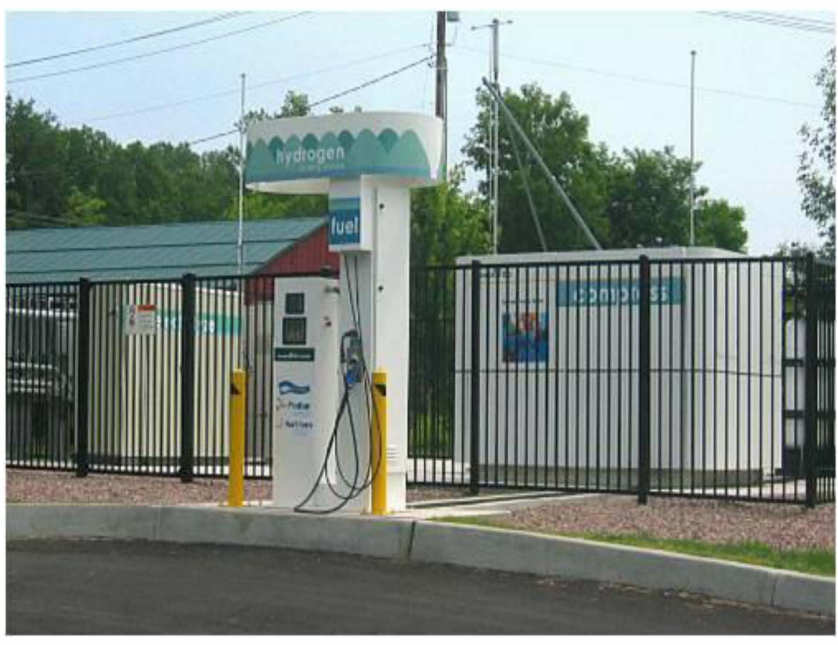

Fig 1 - Fueling Station Hydrogen Gas Dispenser

To replace the original electrolyzer, NASA Kennedy Space Center (KSC) provided a newer electrolyzer unit, also from Proton. This unit included system upgrades, as well as Proton's support, which made this a much more attractive option for the fueling station.

In order to use the equipment, it was necessary to refurbish many of the main components, including the electrolyzer, as it had been in storage or exposed to the elements and gone unused for several years. OAI arranged for decommission of the equipment in the fall of 2010 and equipment was shipped to the appropriate original equipment manufacturers. Arrangements were also made to ship KSC's electrolyzer to Proton for refurbishing.

\section{Project Phase II}

As Phase I of this project was coming to a close, NASA's Enabling Technology Development and Demonstration (ETDD) Program's High Efficiency Space Power Systems (HESPS) Project was able to provide additional funding to continue work towards installing the hydrogen fueling station. Through HESPS, the overall goals for the project remained virtually unchanged, although a much larger focus was placed on NASA's ability to not only install the hydrogen fueling station, but make visible other types of NASA-developed technologies. With these goals in mind, NASA GRC assumed the responsibility of managing the project in December 2010, as well as providing safety support from NASA safety experts from GRC and $\mathrm{KSC}$.

At this point, OAI had already made significant progress towards the final purchasing arrangements for the fueling station equipment from E-Vermont. With equipment close at hand, discussions with the GCRTA became more critical. Meetings had been held with the GCRTA to discuss site selection criteria, and initial plans had been made to install the station at the GCRTA Triskett Rapid Station. However, after an on-site walk-through with GCRTA, OAI, and NASA personnel, it was determined that due to the lack of plumbing and electrical conduits to the station area, Triskett was not a viable option. After further discussion and site visits, the Hayden facility was determined as the final site for the hydrogen fueling station. The Hayden facility garage serves to house a large portion of GCRTA's bus fleet in East Cleveland. The facility is visible to the public as it sits directly along the GCRTA's Rapid Transit Red line across from the Louis Stokes Rapid Station at Windermere. Hayden lent itself well to the needs of the hydrogen fueling station, as the facility had previously housed GCRTA's compressed natural gas (CNG) fleet of buses and had a large outdoor, fenced-in area with concrete pads for equipment placement. This meant fewer site and facility modifications would need to be made prior to installation of the system. The outfitting of the garage to house CNG buses also lent itself well to the transition to housing a hydrogen fuel cell bus.

With equipment purchase agreements close to being finalized and site selection complete, NASA GRC then focused on plans for installation. Local NASA contractor, Sierra Lobo, Inc. (SLI), was tasked with the installation of the fueling station, along with the plan development, site preparation and code compliance necessary to perform the installation. SLI has been working on developing sitespecific plans for the fueling station, arranging for the refurbishing of equipment, and drawing up hazard analyses for the project over the past several months.

During this phase of the project, GCRTA also delved further into discussions with the United Technologies Corporation (UTC) Power. Prior discussions with UTC had led to arrangements to provide a fuel cell bus to GCRTA for a lease period of one year. GCRTA has 
continued to work with UTC to make arrangements for the bus and determine the facility and maintenance requirements for the vehicle.

\section{TECHNOLOGY DEMONSTRATION}

\section{A. Fuel Cells}

There are various types of fuel cells, all useful for different applications based on their operating parameters.

Proton Exchange Membrane fuel cells, more widely known as PEM fuel cells, are a means of power generation useful for both space and terrestrial applications. The PEM fuel cell converts the chemical energy of hydrogen and oxygen into electrical energy with heat and water as byproducts of the electrochemical reaction. Hydrogen enters at the anode (negative electrode) and is split into hydrogen ions. DC electricity is produced by drawing electrons through an external circuit from the anode (negative) to the cathode (positive). Oxygen (air) enters at the cathode and combines with hydrogen ions to produce water and heat, which is then removed from the fuel cell. Fig. 2 illustrates the operation of a PEM fuel cell.

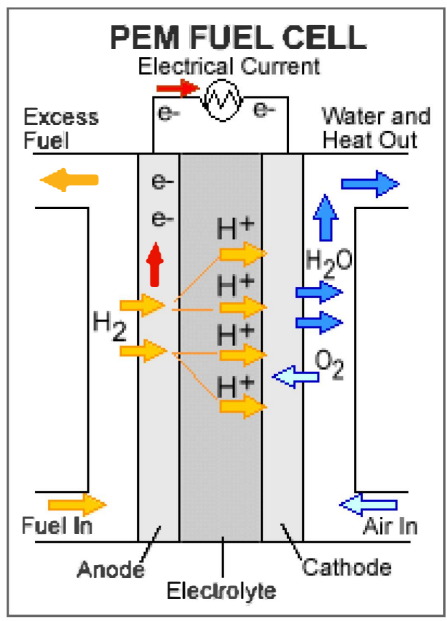

Fig 2 - PEM Fuel Cell Operation

For in-space applications, hydrogen and oxygen gases are stored in external storage tanks, allowing the fuel cell to generate power as long as fuel is available. For terrestrial applications, air is substituted for stored oxygen, eliminating the need to generate/purchase and store oxygen gas. In a fuel cell bus, such as the bus being leased to GCRTA by United Technologies for this project, a rendering of which is in Fig. 3, the diesel engine is replaced with an electric motor and a fuel cell to generate the power necessary to run the bus. Advantages of replacing the engine with a fuel cell/electric drive train include the elimination of harmful emissions (only heat and water are emitted), reduction of moving parts, and virtually silent operation.

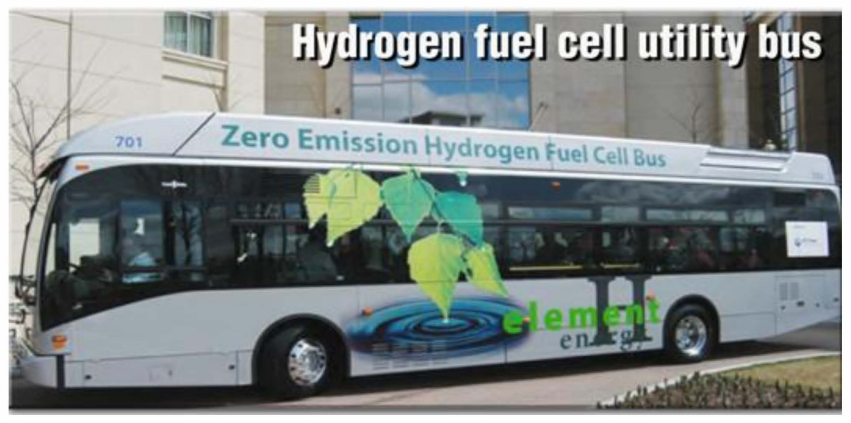

Fig 3 - Fuel Cell-Powered Bus

\section{B. Electrolysis}

In contrast, the reverse reaction of splitting water into hydrogen and oxygen is called electrolysis. The hydrogen fueling station employs an electrolyzer system to generate the hydrogen necessary to fuel the PEM fuel cell in the bus. The electrolyzer intakes city water, purifies it via an internal de-ionizing process, and uses electricity to split the water into hydrogen and oxygen gases. The generated hydrogen is then compressed and stored in tanks to be pumped to the hydrogen storage tank on the bus for use in the fuel cell. Electrolysis is a safe, efficient, and clean method of generating hydrogen gas since there are no harmful emissions. The uses for the generated hydrogen gas are not limited to only fuel cell buses, but passenger vehicles, utility vehicles, and stationary power systems that also employ fuel cells.

\section{System-specific Details}

The equipment purchased by OAI for this project was originally installed in Burlington, VT for a very similar purpose of fueling a fuel cell vehicle. Although the original electrolyzer will not be used for this project and is being replaced with a newer model, both models were built by Proton and produce a nominal 12 kilograms of hydrogen per day. The biggest advantage of this system is that it allows for several electrolyzer units to be hooked up in parallel operation. So, although the system can only produce 12 kilograms of hydrogen per day, in the future the electrolyzer can be replaced with a larger unit with more capacity, or several additional units to increase output. The hydrogen is compressed and stored in storage tank arrays to which additional tanks may be added for increased storage volume.

The dispenser is a stand-alone unit with pin-restricted access and automated control. The dispenser operates similarly to a typical gasoline pump. The bus is driven up alongside the dispenser, the nozzle securely connects to the 
bus using a pressure-sealed flange to the hydrogen storage tank on the bus, and the bus fills with hydrogen.

For the current project, the hydrogen generation system will draw from the city's power grid to provide the power necessary to run the system. However, the system is fully amenable to renewable energy sources as its source of electricity, which would make it a truly "green" system, generating carbon-free fuel independent of coal-fired power plants, reducing the country's dependence on fossil fuels.

\section{NASA Technology}

A large part of this installation project is technology demonstration-related. Over the past several decades, NASA has significantly contributed to the development of fuel cell technology by supporting fuel cells for the Gemini, Apollo, and Space Shuttle programs [1]. NASA is currently working on developing and improving fuel cell technologies for both in-space and terrestrial applications. Current PEM fuel cell and electrolysis research at NASA GRC is focused on improving the reliability and efficiency of the systems. This development has the potential to be incorporated into this station, or similar systems, as the technology becomes more advanced.

NASA is also demonstrating newly-developed sensor technology on the system. Under Small Business Innovation Research (SBIR) and Small Business Technology Transfer (STTR) program funding, Makel Engineering, Inc. helped to develop miniature, high-tech hydrogen gas sensors. Sensors such as these have multiple uses in different environments, including uses such as this, where the sensor may be placed on the hydrogen dispenser and exposed to the Cleveland elements year-round. Makel has since commercialized this product and will be collaborating with NASA GRC to install several of these units on and around the hydrogen fueling station equipment and GCRTA facility.

These kinds of technology demonstrations make visible to the public that NASA technologies are not only useful for space and aeronautics applications, but terrestrial applications as well.

\section{CURRENT STATUS AND FUTURE PLANS}

At the current time, NASA GRC and Sierra Lobo are working with Proton On-Site and Air Products and Chemicals, Inc. to get equipment refurbished and shipped to Cleveland for delivery to the GCRTA Hayden facility. Since most of the equipment had been stored outdoors and gone unused for several years, this was a necessary step in the process to ensure proper operation of the system once it is installed at Hayden. Plans are being developed with GCRTA to perform facility modifications necessary to house the hydrogen fuel cell bus and install the equipment at the Hayden site. Once these two tasks are completed, equipment will be shipped to Hayden to begin installation. GCRTA plans to have the hydrogen fuel cell bus delivered around the time the station equipment installation is complete, allowing for immediate operation of both the bus and the station.

As the project continues, many opportunities will be opened up to showcase this technology. The installation of this system allows for the great opportunity to demonstrate the safe and efficient means of producing hydrogen gas via electrolysis to use as an alternative means of fueling vehicles. The community will be able to not only see the bus in operation, but also experience riding on a fuel cellpowered bus first-hand. There are many technology areas related to the fueling station that can be upgraded with continued development, and the hope is that the system will be entirely off the grid and run off renewable energy sources in the future. By late spring of 2012, Ohio will have its first electrolysis-based hydrogen fueling station operating in Cleveland, and hopefully the first of many.

\section{ACKNOWLEDGMENT}

The author would like to thank the many collaborators on this project, including the Cleveland Foundation, Ohio Aerospace Institute, Greater Cleveland Regional Transit Authority, Sierra Lobo Inc., Makel Engineering Inc., UTC Power, and NASA Kennedy Space Center.

\section{REFERENCES}

[1] J. H. Scott, " The Influence of NASA's Human Spaceflight Program on the Development of Fuel Cell Technology," in Proc. 2008 6th International Energy Conversion Engineering Conference (IECEC), AIAA 2008-5793.

\section{BIOGRAPHIES}

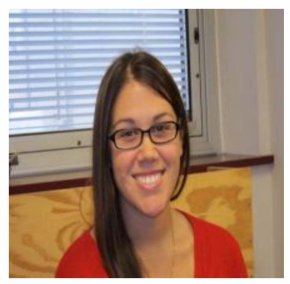

Brianne T. Scheidegger holds a Bachelor's degree in Chemical Engineering from Cleveland State University and is currently working towards a Master's degree in the same field. She began her career in the NASA Glenn Research Center's Electrochemistry Branch in 2009. Much of her work has focused on testing lithium-ion battery materials and cells. She is the task lead for the hydrogen fueling station project under the Space Power Systems project. Recent research has focused on the area of advanced PEM fuel cell technology and demonstrations. 